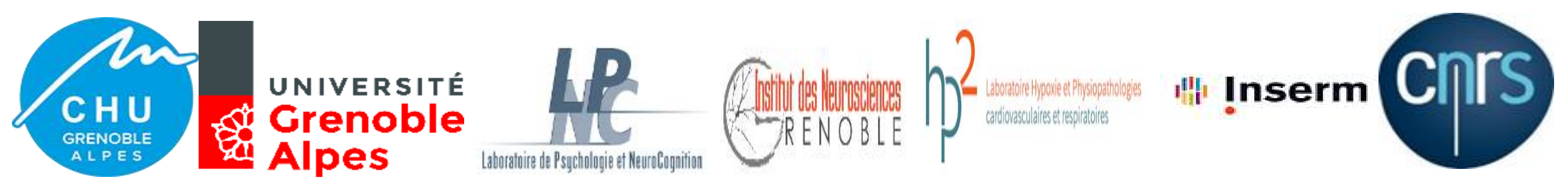

\title{
Handicap in Adults with Arthrogryposis is Severe, multifaceted, Partly Invisible and Varies by Genotype
}

Shenhao Dai, Klaus Dieterich, Marie Jaeger, Emmanuelle Clarac, Bernard Wuyam, Pierre-Simon Jouk, Dominic Pérennou

Departments of PMR and of Medical genetics, University Hospital Grenoble-Alpes, France

\section{- Introduction}

Arthrogryposis multiplex congenita (AMC) is a disease characterized by the presence of at least two joint contractures at birth in different body areas. This study is the first to describe disability patterns of a cohort of adults with AMC.

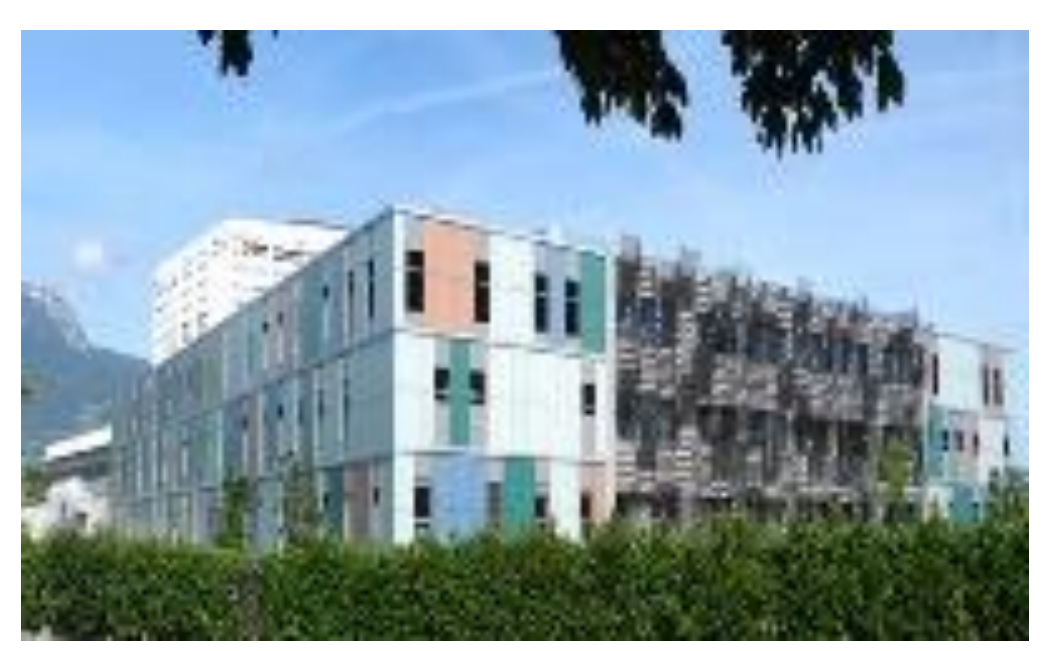

\section{- Methods}

Retrospective analysis of data for unselected persons with AMC referred to the French center for adults with AMC from 2010 to 2016. All underwent a pluri-professional systematic and comprehensive investigation of deficits, activity limitation, and participation restriction according to the International Classification of Functioning, Disability and Health and genetic analysis when indicated. Participants were divided by Amyoplasia and other AMC types.

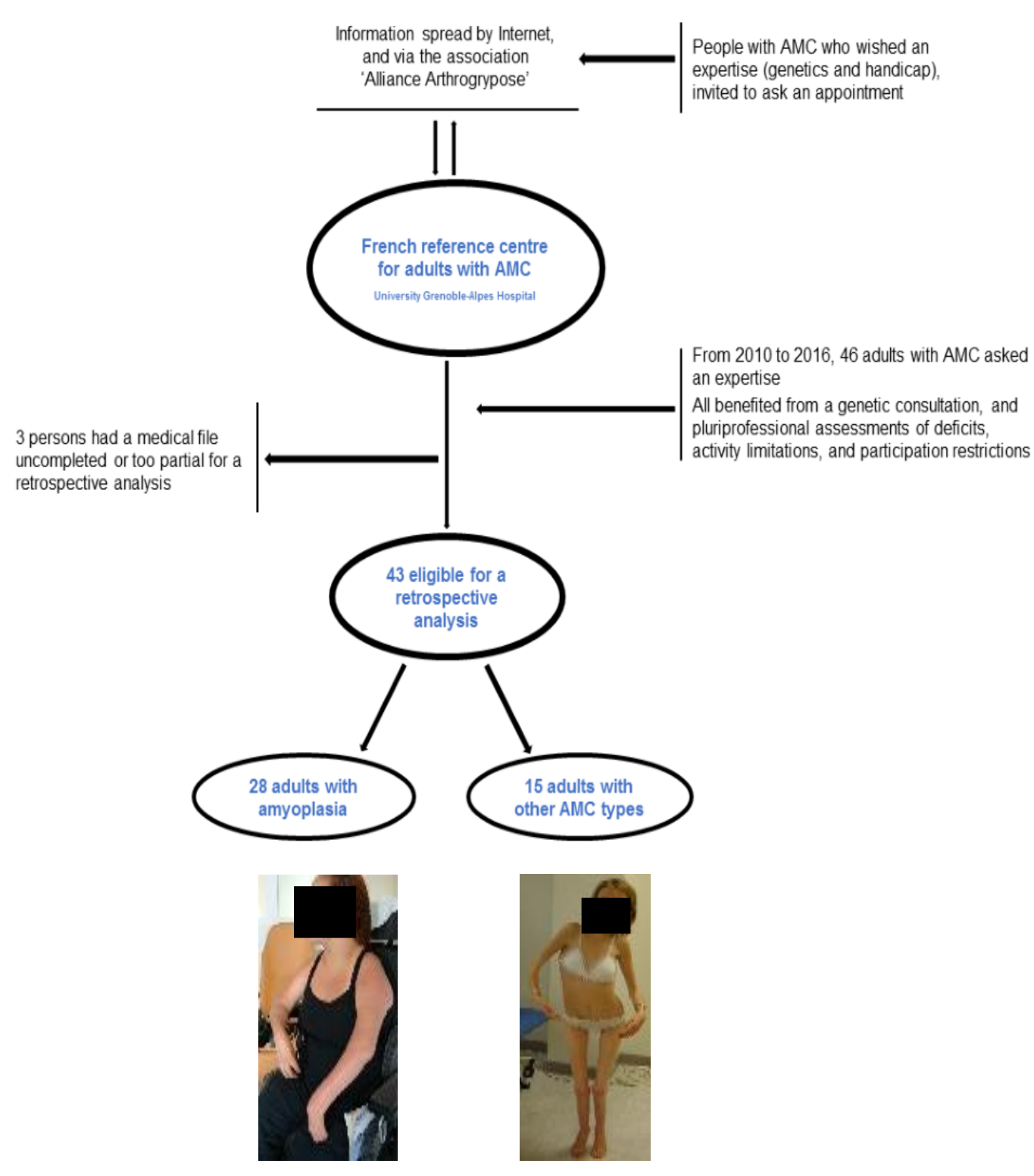

- Results

Muscle weakness

Joint stiffness
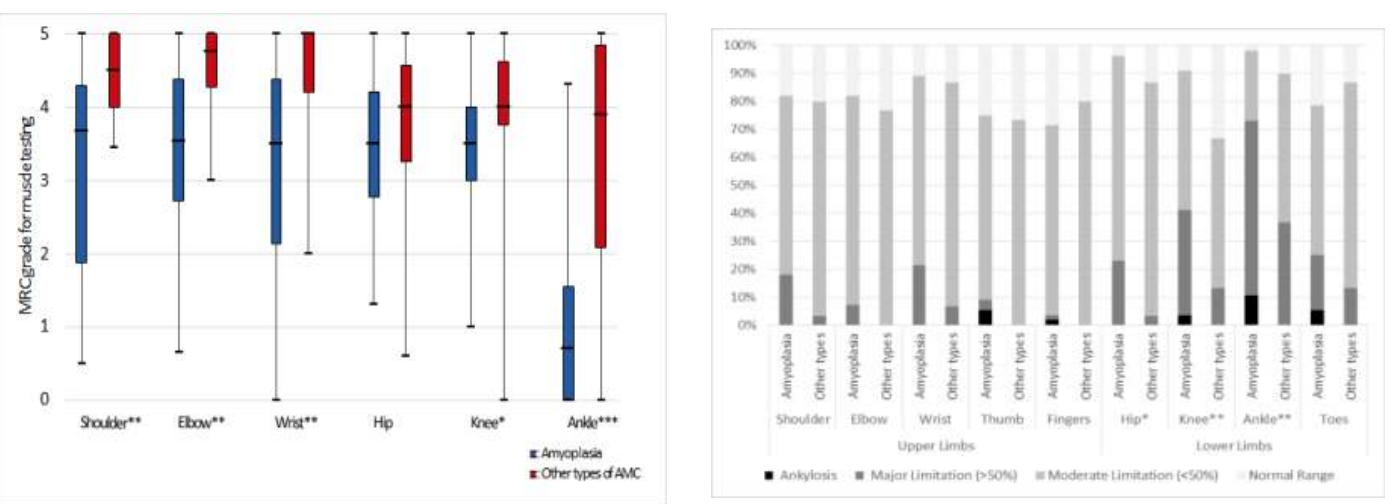

Respiratory impairment

Severe respiratory disorders were infrequent and were linked to PIEZO2 mutations. Respiratory function was better with Amyoplasia than other AMC types (FVC 3.8 [3-4.3] vs 2.2 [1.42.7], $p<0.001)$.

Swallowing and speech disorders

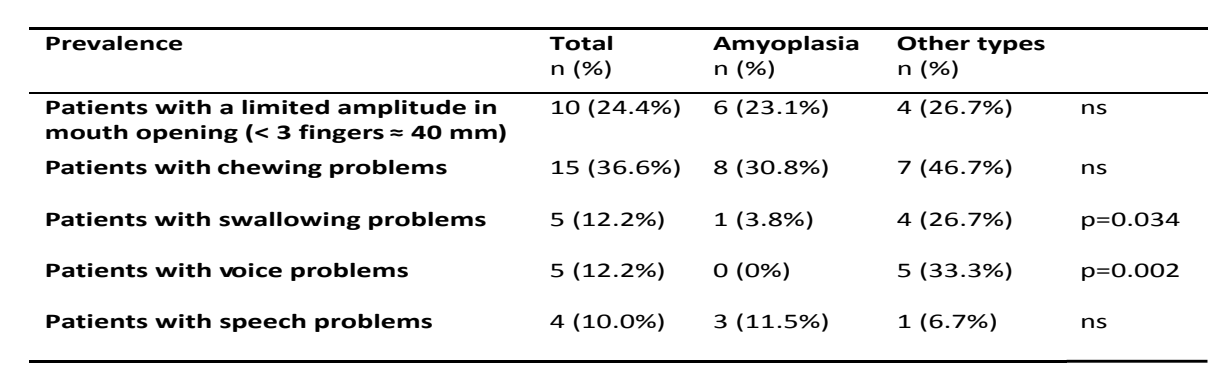

Pain and psychological suffering

About $91 \%$ of patients complained of pain, other principle psychological problems were: anxiety (43\%), fatigue (34\%), difficulty in sexual life $(24 \%)$, altered self-esteem $(17 \%)$, and feeling of solitude (15\%).

Activity limitations

As shown in fig, most patients had modified independence with FIM 113 \pm 13.9. Patients with Amyoplasia had lower FIM sores than patients with other types of AMC $(110.4 \pm 16.3 \mathrm{vs}$ $118.1 \pm 4.8, p=0,26)$. Nearly all patients had high scores at the Cognitive FIM (34.8 \pm 0.6$)$.

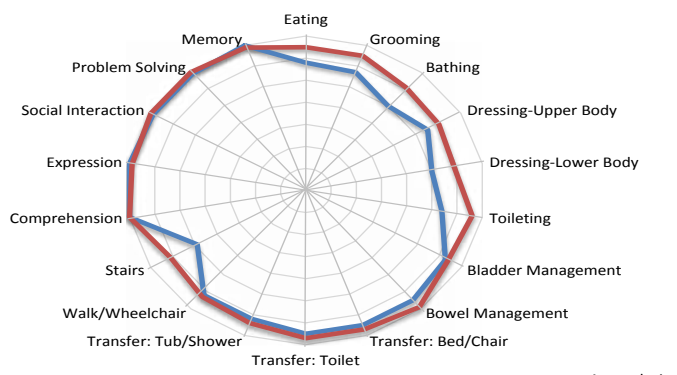

Mobility

Most participants with AMC (88\%) could walk independently. Gait disorders were not due to respiratory impairment but to skeletal problems and were always associated with Amyoplasia when severe.

Participation restriction

\begin{tabular}{llll}
\hline & $\begin{array}{l}\text { Amyoplasia } \\
(\mathrm{n}=28)\end{array}$ & $\begin{array}{l}\text { Other types } \\
(\mathrm{n}=15)\end{array}$ & $\mathrm{p}$ \\
\hline Occupation & & & \\
Work & $14(50 \%)$ & $8(53 \%)$ & $\mathrm{ns}$ \\
Student & $7(25 \%)$ & $3(20 \%)$ & $\mathrm{ns}$ \\
unemployed & $7(25 \%)$ & $4(27 \%)$ & $\mathrm{ns}$ \\
Technical assistance & $17(61 \%)$ & $4(27 \%)$ & $\mathrm{ns}$ \\
$\quad$ Human help & $12(43 \%)$ & $5(33 \%)$ & $\mathrm{ns}$ \\
Driving & $15(54 \%)$ & $13(87 \%)$ & $\mathrm{p}=0.03$ \\
\hline
\end{tabular}

\section{Conclusion}

This study describes disability patterns of a cohort of adults with AMC by genotype. The handicap of adults with AMC is influenced by genotype, with an important invisible handicap. 